\title{
DESENVOLVIMENTO DE PROJETO DE AUTOMAÇÃO DE UMA PLANTA DE MANUFATURA UTILIZANDO METODOLOGIA GRAFCET E IMPLEMENTAÇÃO EM LINGUAGEM LADDER
}

Nathália M. Albuquerque - nmartinsalb@gmail.com

SérgioS.Leal - sergioleal@recife.ifpe.edu.br

Gideão P. Oliveira - gideao.oliveira@recife.ifpe.edu.br

Rafael C.Ramos-rafaelcalado@live.com

Instituto Federal de Educação, Ciência e Tecnologia de Pernambuco

Av. Prof. Luís Freire, $n^{\circ} 500$ - Cidade Universitária

50740-545 - Recife - PE

Resumo: A automação pode ser definida como a tecnologia por meio do qual um processo ou procedimento é alcançado sem a assistência humana. A arte de controlar é tão antiga quanto às necessidades humanas de desenvolver seus próprios sentidos. Mesmo não dispondo de grandes tecnologias, o homem mantinha a qualidade em seus artefatos e desenvolvia projetos eficazes direcionados ao controle de suas exigências. Há muitos equipamentos que compõem a automação direta e indiretamente, mas o controlador lógico programável (CLP) é um dos mais importantes. O CLP surgiu no final dos anos 60 na indústria automotiva com a finalidade de abreviar os tempos de parada das máquinas na produção, uma vez que, a linha de montagem era dinâmica em relação ao modelo de carro a ser produzido e uma simples mudança na produção, significava mudanças nas conexões elétricas entre os relés eletromecânicos nos enormes painéis de controle. O presente artigo tem como propósito o desenvolvimento de um projeto de automação de uma planta de manufatura de peças utilizando o CLP da família S71200 da Siemens. Foi utilizada a metodologia GRAFCET, uma vez que o processo é essencialmente sequencial, como o CLP utilizado não oferece suporte a essa linguagem de programação, após a confecção dos diagramas GRAFCET, os mesmos foram implementados em linguagem Ladder. Foram exploradas diversas etapas necessárias para o desenvolvimento de um projeto de automação, desde a análise detalhada do funcionamento do sistema à programação do controlador no ambiente de programação TIA Portal da Siemens.

Palavras-chave: Controle e Automação. CLP. GRAFCET. Linguagem Ladder.

\section{INTRODUÇÃO}

Os aspectos dos sistemas de manufatura, ou sistemas de produção, são mais importantes atualmente do que jamais foram. A palavra 'manufatura' tem sua origem em duas palavras latinas, manus (mão) e factus (fazer), e a combinação de ambas significa 'fazer com as mãos'. Era assim que se realizava a produção quando a palavra surgiu na língua inglesa, por volta de 1567. Com a revolução industrial, os métodos artesanais deram lugar às máquinas. Os produtos tornaram-se mais complexos, assim como os processos (GROOVER, 2010).

Até década de 60, os dispositivos eletromecânicos foram os recursos mais utilizados para efetuar controles lógicos e de intertravamentos nas linhas de produção e em máquinas isoladas. Tais dispositivos tinham especial importância na indústria automobilística em que a complexidade dos processos produtivos exigia instalações de grandes painéis com centenas de 
relés e um grande número de interligações entre eles. Devido à complexidade desses painéis, a indústria automotiva suspendia a atividade produtiva toda vez que mudava a produção de um modelo de montagem do mesmo tipo de automóvel. Surgiu então o primeiro CLP com a finalidade de diminuir o tempo de parada das máquinas na produção. A utilização dessa nova tecnologia permitiu que as alterações feitas na linha de montagem fossem feitas mudando a programação do CLP, não necessitando alterar as conexões elétricas dos painéis (SILVEIRA, 2002).

O presente trabalho tem como proposta o desenvolvimento de um projeto de automação do Sistema Flexível de Manufatura - DK8, composto por três Células mecatrônicas, que simulam um ambiente industrial responsável pela manufatura de peças. Para controlar esse sistema será utilizado um CLP da Família S7-1200 da Siemens.

O desenvolvimento trará uma síntese de como foi realizado o projeto de automação, a linguagem de programação e a metodologia utilizada, o ambiente de programação e os detalhes das configurações para a implementação do projeto.

A motivação para abordar o tema surgiu da universalização do uso do CLP em processos e operações industriais, controle de máquinas individuais, células de máquinas e sistemas automatizados diversos. Sendo indispensável o conhecimento adquirido neste trabalho para o profissional que irá atuar na área de controle e automação industrial. Como resultado, esperase não só apenas um conhecimento mais amplo na área de automação de processos, mas também criar um legado que auxilie outras pessoas no desenvolvimento de tais competências.

\section{DESENVOLVIMENTO}

O Sistema Flexível de Manufatura - DK8 é composto por três Células mecatrônicas, como pode ser visto na figura 1. É um sistema totalmente flexível e modular desenvolvido para o estudo da automação industrial. A utilização das células pode ocorrer de forma independente ou integrada, através da junção das mesmas. Permite formar um sistema de automação industrial integrado e complexo. Os recursos e equipamentos disponíveis são os mesmos do ambiente industrial, fazendo com que a experiência vivenciada com o sistema fique muito próxima de uma experiência real na indústria.

Figura 1 - Sistema Flexível de Manufatura - DK8

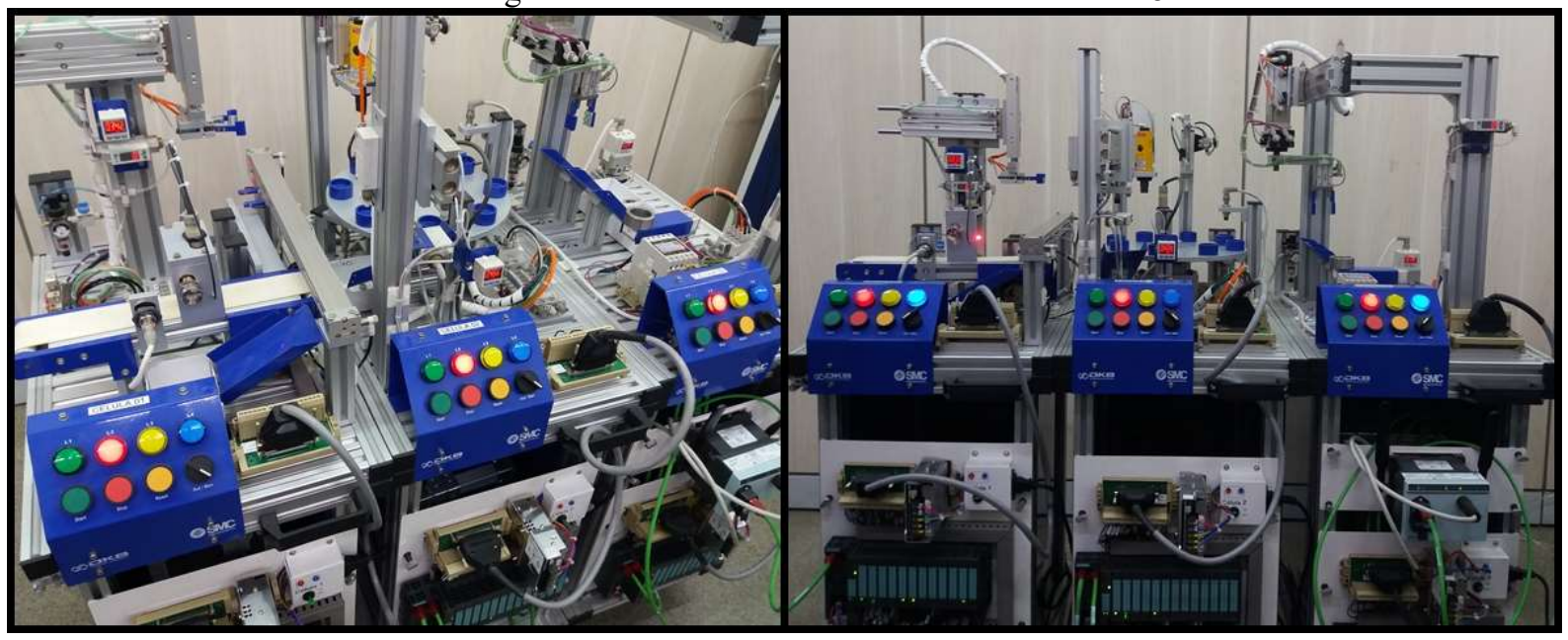

Fonte: Autoral

Para este estudo, serão utilizadas as três células trabalhando de forma integrada e configurando um sistema de manufatura de peças. A célula 1 será responsável pela separação da matéria prima, a célula 2 pela manufatura da peça e a célula 3 pelo armazenamento do 
produto final. Alguns sensores e atuadores presentes na planta não serão necessários para a aplicação proposta.

Para o controle do Sistema Flexível de Manufatura será utilizado um CLP Siemens S71200 CPU 1214C DC/DC/DC (Figura 2.a), todos os sensores e atuadores de cada célula serão levados para unidades remotas de I/Os Siemens ET 200S com comunicação PROFINET (Figura 2.a). O CLP e as Remotas irão integrar uma rede de comunicação PROFINET.

Figura 2.- (a) CLP S7-1200 e (b)Remota Profinet ET 200S
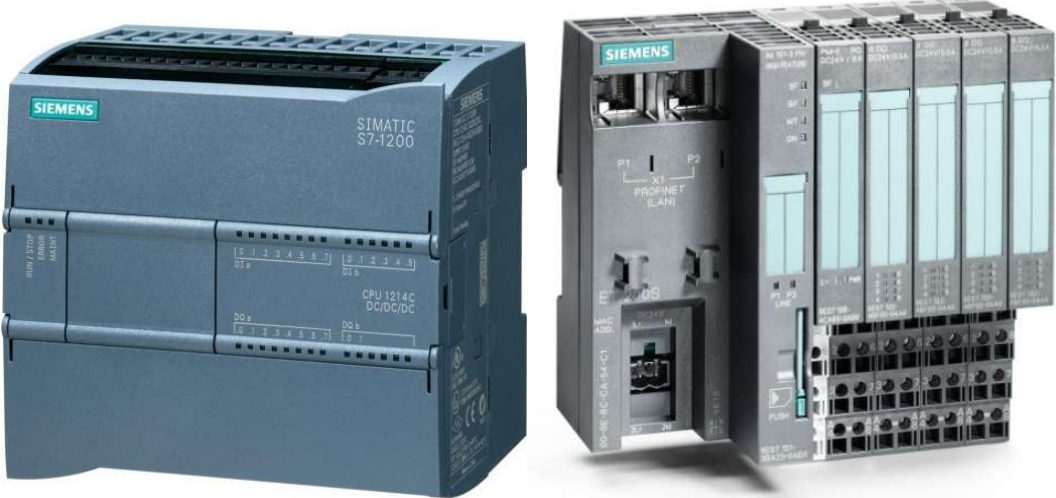

Fonte: http://media.rs-online.com/t_large/R6683064-20.jpg (2017)

Para programar o CLP será utilizado o software TIA Portal - Totally Integrated Automation v. 12 da Siemens, que unifica todas as ferramentas de automação Siemens em um único ambiente de desenvolvimento. A Figura 3 mostra a representação do CLP e das remotas no TIA Portal.

Figura 3 - Projeto desenvolvido no TIA Portal, detalhe da rede PROFINET

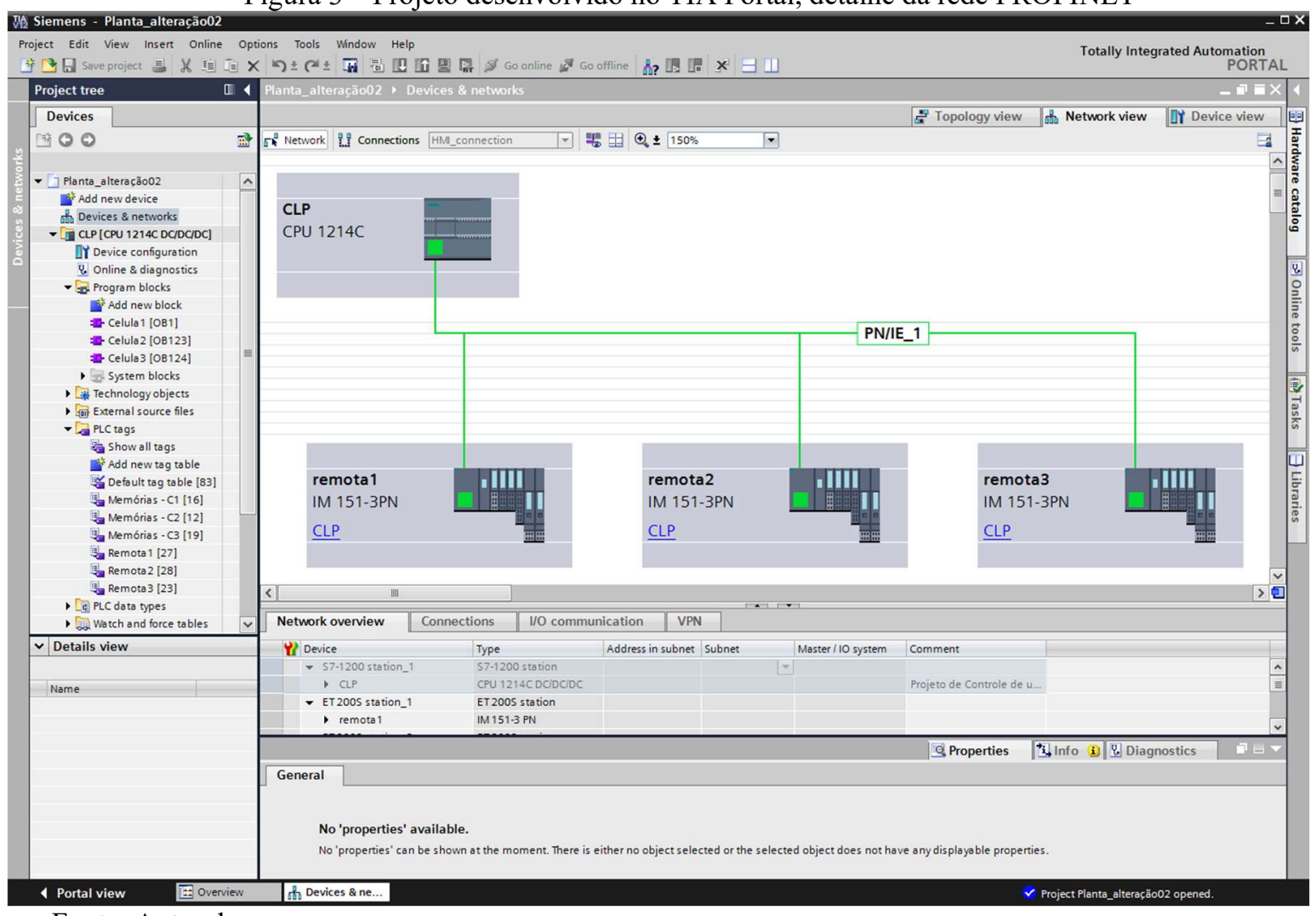

Fonte: Autoral 


\subsection{Linguagem de programação e metodologia utilizada}

O TIA Portal só permite programar o CLP S7-1200 em linguagem Ladder, linguagem de diagrama de blocos de funções ou em texto estruturado. Por opção do programador foi escolhida a linguagem Ladder, devido à sua semelhança com o diagrama de Relés, amplamente utilizado por técnicos e engenheiros da área.

Entretanto, pelo fato do processo ser sequencial, a melhor linguagem para a resolução do problema proposto seria o Sequenciamento Gráfico de Funções. Mesmo sem o Sequenciamento Gráfico de Funções ser suportado pelo S7-1200, a metodologia GRAFCET ainda pode ser utilizada, após a elaboração do diagrama GRAFCET, este pode ser implementado em Ladder com as devidas representações dos estados, transições e ações.

A implementação de GRAFCET em linguagem Ladder representa um aumento no número de linhas de comando quando comparada à resolução direta utilizando lógica de programação em Ladder, mas representa também uma melhor estruturação do programa, facilitando e agilizando o desenvolvimento do projeto, melhorando a detecção de erros durante a elaboração da solução, como também, facilitando a compressão por partes de outros programadores familiarizados com a metodologia.

Com a evolução da tecnologia, passou-se a dar maior importância à manutenção, flexibilidade e documentação, não importando que para isso a solução implementada não fosse exatamente a de menor extensão em termos de ocupação de memória, o que torna o uso da metodologia GRAFCET na programação de CLPs viável, ainda que o CLP não ofereça suporte a esta linguagem (SILVEIRA, 2002).

\subsection{Elaboração do Diagrama GRAFCET}

As três células operam de forma quase independente, apenas quando for ocorrer o transporte de peças de uma célula para outra, deve-se verificar se a próxima célula está apta para receber a peça. Desta forma, será elaborado um diagrama GRAFCET para cada célula, e não um único diagrama que permitiria apenas uma peça por vez no Sistema de Manufatura.

A partir das informações do processo de fabricação das peças no Sistema de Manufatura, a elaboração do diagrama GRAFCET consiste na criação de uma representação de estados em que são realizadas certas ações, e a definição das condições necessárias para a transição entre os estados, essa representação se assemelha a um fluxograma do funcionamento da célula.

Figura 2 - Trecho do Diagrama GRAFCET da Célula 2

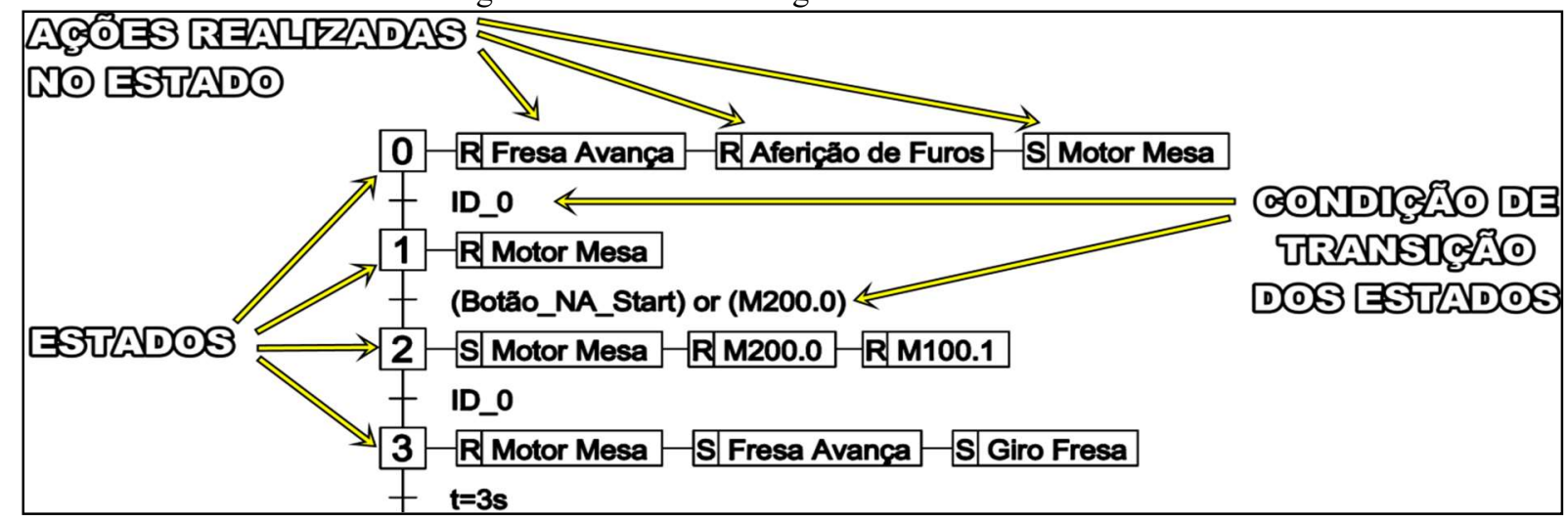

Fonte: Autoral

Na Figura 4, onde mostra um trecho do Diagrama GRAFCET da Célula 2, pode-se observar que, no estado 0, o avanço da fresa e o carimbo das peças (aferição de furos) recebem um sinal de reset e o giro da mesa recebe um sinal de set. A transição ocorre quando o sensor indutivo 
que detecta o giro da mesa (ID_0) é acionado, levando então para o estado 1, onde permanece até que o botão de Start da célula seja acionado ou que a Célula 1 informe que existe uma peça para ser processada pela Célula 2 (sinal dado por M200.0).

\subsection{TIA Portal}

O TIA Portal Siemens é a nova geração de software de engenharia para a automação industrial. O primeiro software de automação industrial com "um único ambiente de engenharia" - um projeto de software para todas as tarefas de automação (SIEMENS, 2016). O TIA Portal é o ambiente de programação do S7-1200.

A Figura 5 mostra uma visão geral do ambiente de programação do TIA Portal, depois de adicionar o CLP que será utilizado, deve-se adicionar as remotas e montar a rede PROFINET, como foi exibido na Figura 2.

Figura 3 - Visão Geral do ambiente de trabalho do TIA Portal

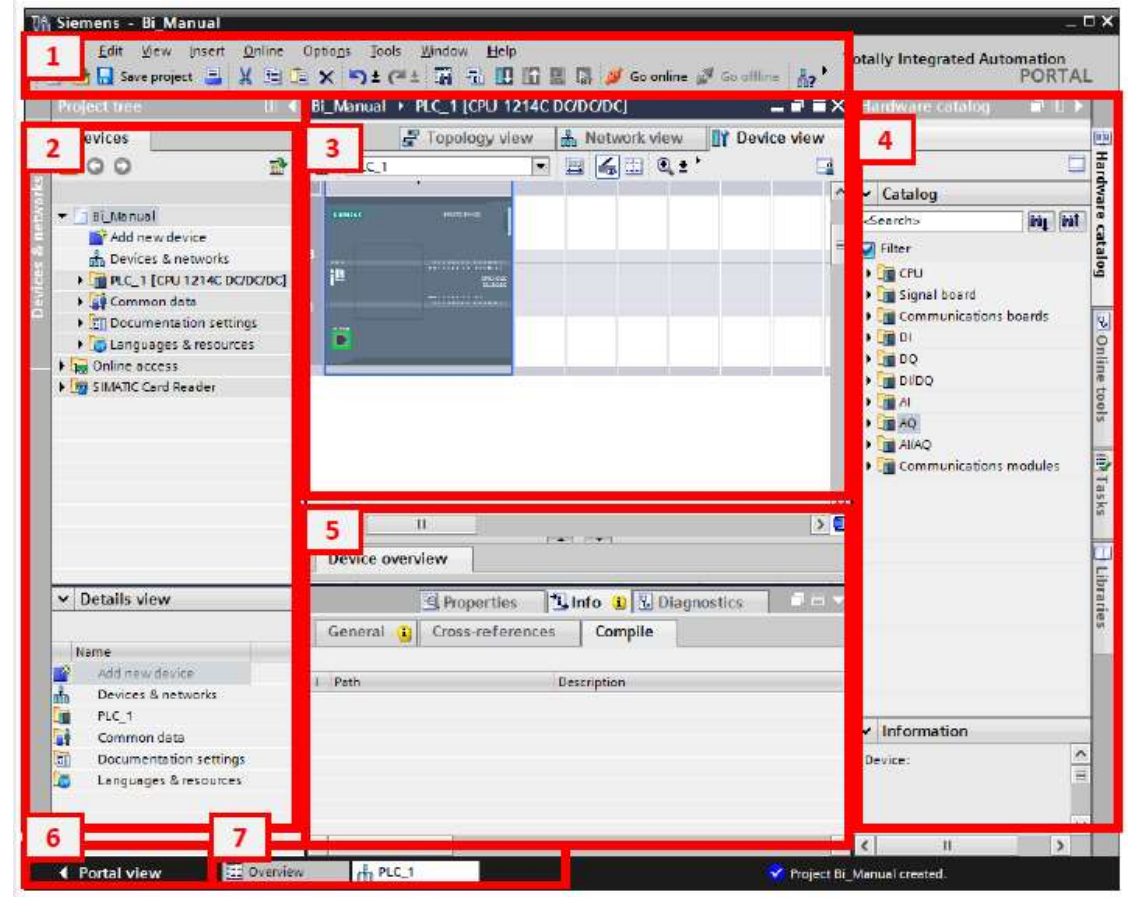

1- Menus e barra de ferramentas

2- Navegador de projeto

3- Área de trabalho

4-Cartões de tarefas

5-Janela de Inspeção

6-Alterar para modo

Portal View

7-Barra de edição

Fonte: Autoral

Para organizar e facilitar a programação, foram criadas as tabelas de tags para nomear todas as entradas, saídas e memórias utilizadas por cada célula, esta ação visa documentar o programa, facilitando a compreensão por parte de outros programadores que poderão dar manutenção na planta de manufatura. Ao todo, foram utilizadas 125 tags, sem estas tabelas ficaria complicado de entender e analisar o programa desenvolvido. Na Figura 6 é apresentada a tabela de tags das memórias utilizadas na Célula 1.

O programa deve ser escritos nos blocos de organização (OB - Organization Block) que formam a interface entre o sistema operacional do controlador (CPU) e o programa de usuário. Eles são chamados pelo sistema operacional e controlam as seguintes operações:

- Processamento cíclico de programa (OB1, OB123, OB124, OB125...)

- Comportamento de start-up do controller (OB100)

- Processamento do programa controlado por alarme

- Tratamento de erros 
"Os desafios para formar hoje o engenheiro do amanhã"

Figura 4 - Tabela de tags das memórias utilizadas pela Célula 1

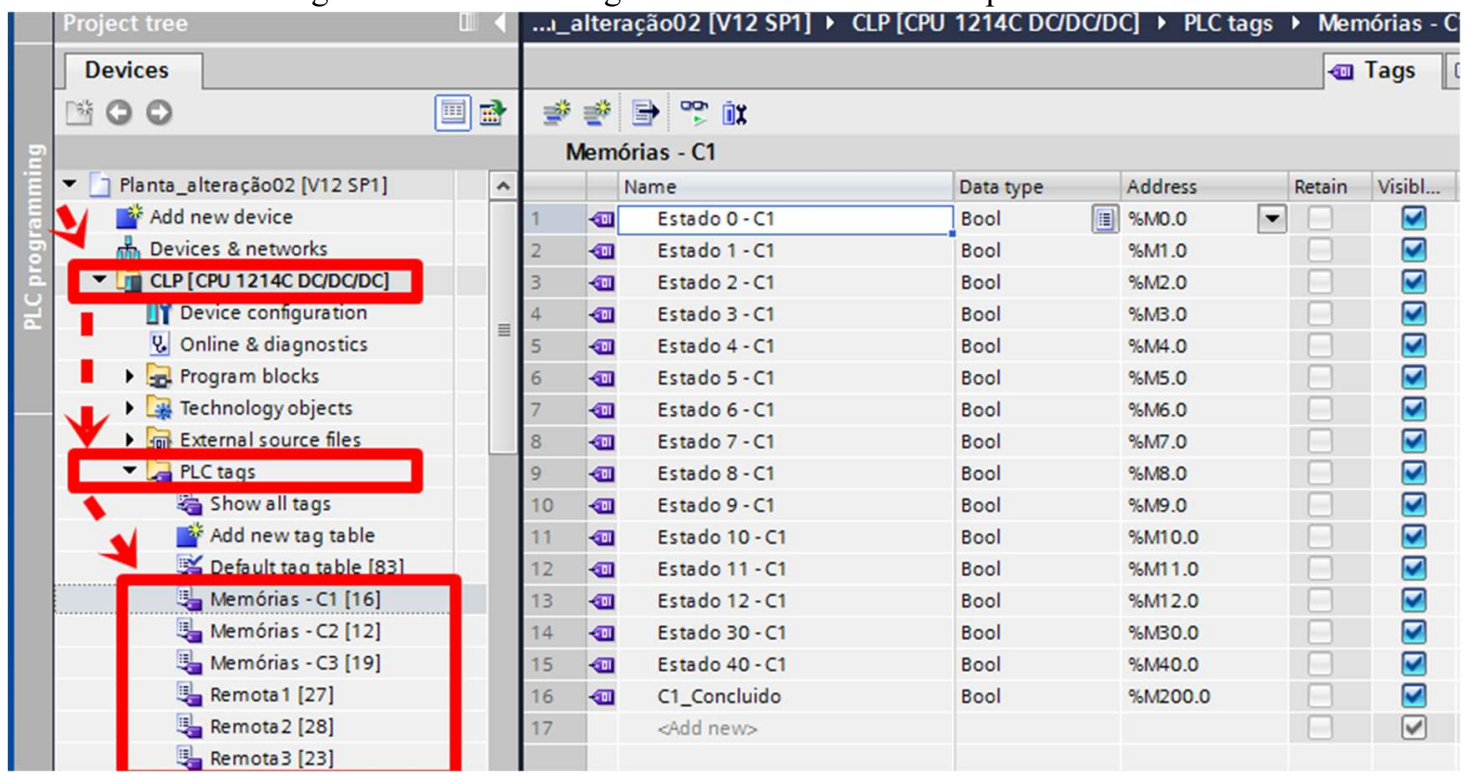

Fonte: Autoral

Em um projeto deve ter pelo menos um bloco de organização para o processamento cíclico do programa. Foi criado então um OB para cada célula, utilizando então o OB1, OB123 e OB124, onde foram implementados em Ladder os diagramas GRACFET das Células. Os OBs ficam localizados na seção Program Blocks do CLP adicionado ao projeto (Figura 7).

Figura 5 - Acesso ao OB1

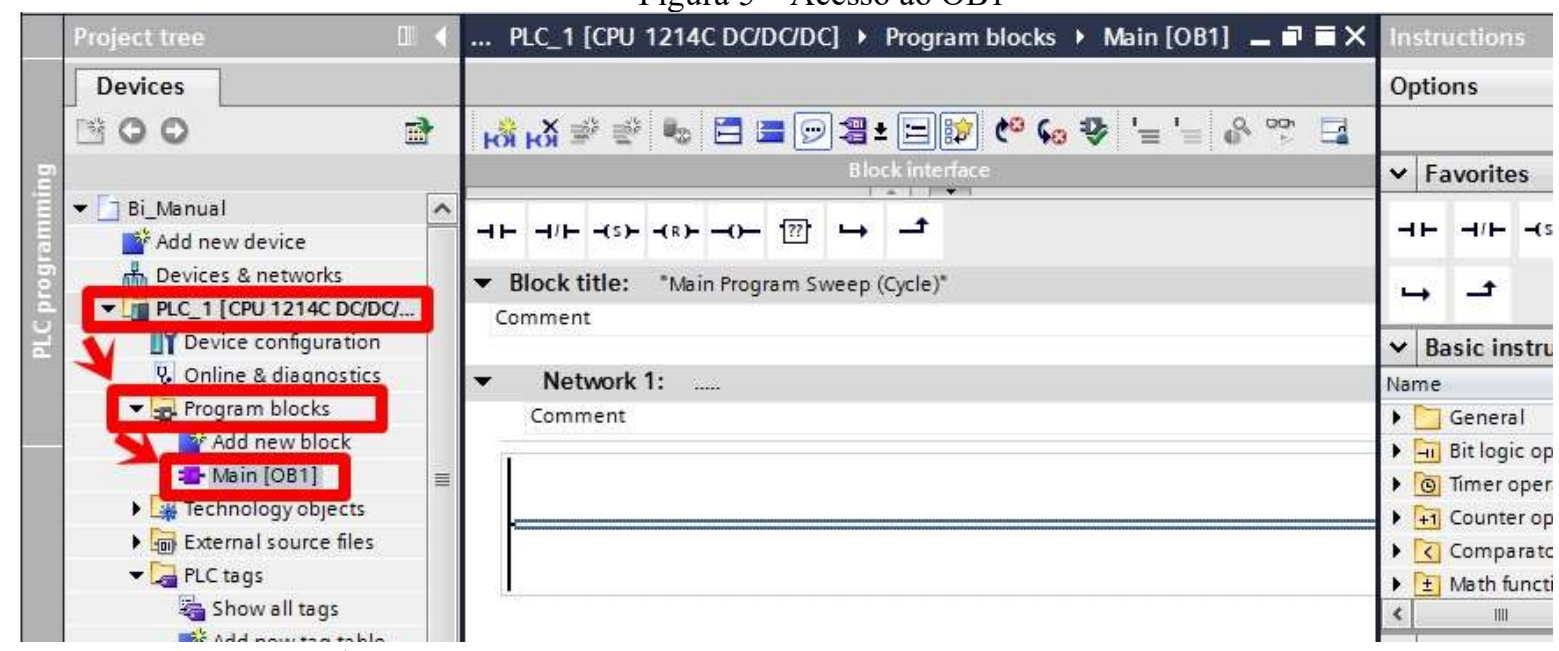

\subsection{Implementação em Ladder}

Após a concepção dos diagramas GRACFET de cada célula, é necessária a conversão e escrita do programa em Ladder. Na estrutura de um GRAFCET, observa-se claramente a existência de três elementos básicos: as transições, os estados e as ações. Assim, se cada um desses elementos for corretamente especificado na programação do CLP, obter-se-á como resultado uma implementação isenta de erros, desde que o GRACFET esteja corretamente modelado.

A implementação do GRAFCET em Ladder é dividida em duas partes distintas: uma responsável pela ocorrência das transições, que define o fluxo do processo, e outra que realizará as ações operativas. 
$\mathrm{Na}$ implementação realizada neste projeto, os estados serão representados por memórias, utilizando como exemplo um trecho do programa da Célula 2 (Figura 8), se a condição de transição do estado 0 para o estado 1 (sensor indutivo ID_0 acionado) ocorrer enquanto o estado 0 estiver ativo, a memória M0.1, que representa o estado $\mathbf{0}$, receberá um sinal de reset e a memória M1.1 receberá um sinal de set levando para o estado 1. Neste momento o programa continuará no estado 1 até que o botão Start (I10.1) ou a memória que indica que a Célula 1 concluiu o seu processo (M200.0) seja acionada.

Figura 6 - Implementação das transições do diagrama GRAFCET em Ladder

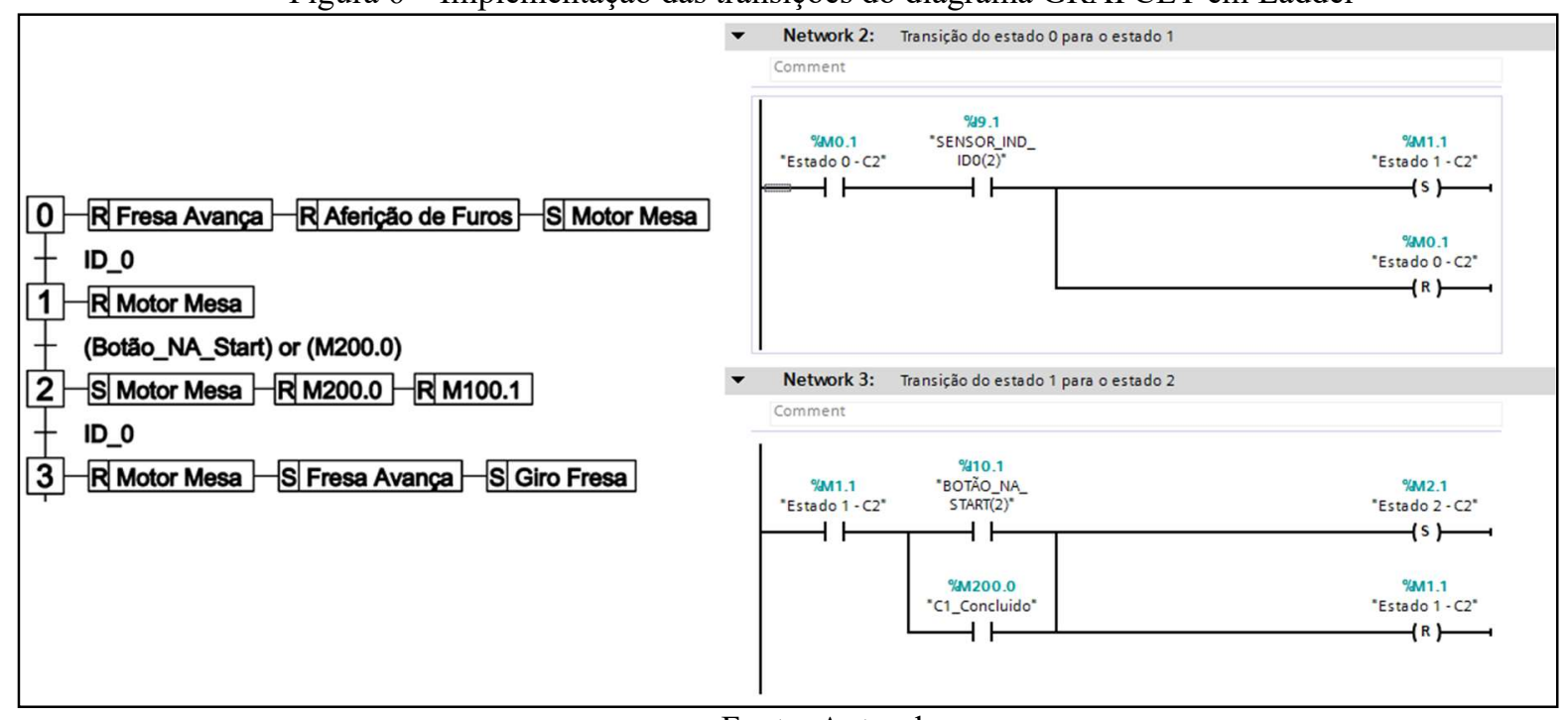

Fonte: Autoral

Após descrever todas as transições, foram descritas todas as ações de cada estado, ainda tomando como exemplo os estados 1 e 2 da Célula 2, pode-se observar na Figura 9 que enquanto o estado 1 (M0.1) estiver ativo, o motor da mesa (Q9.1) receberá um sinal de reset, quando ocorrer a transição para o estado 2 (M1.1) serão executadas as ações de set do motor da mesa e de reset das memórias M200.0 e M100.1.

A ação de tradução do diagrama GRAFCET para o Ladder foi realizada para as três células, o programa completo em Ladder pode ser visto no Apêndice D.

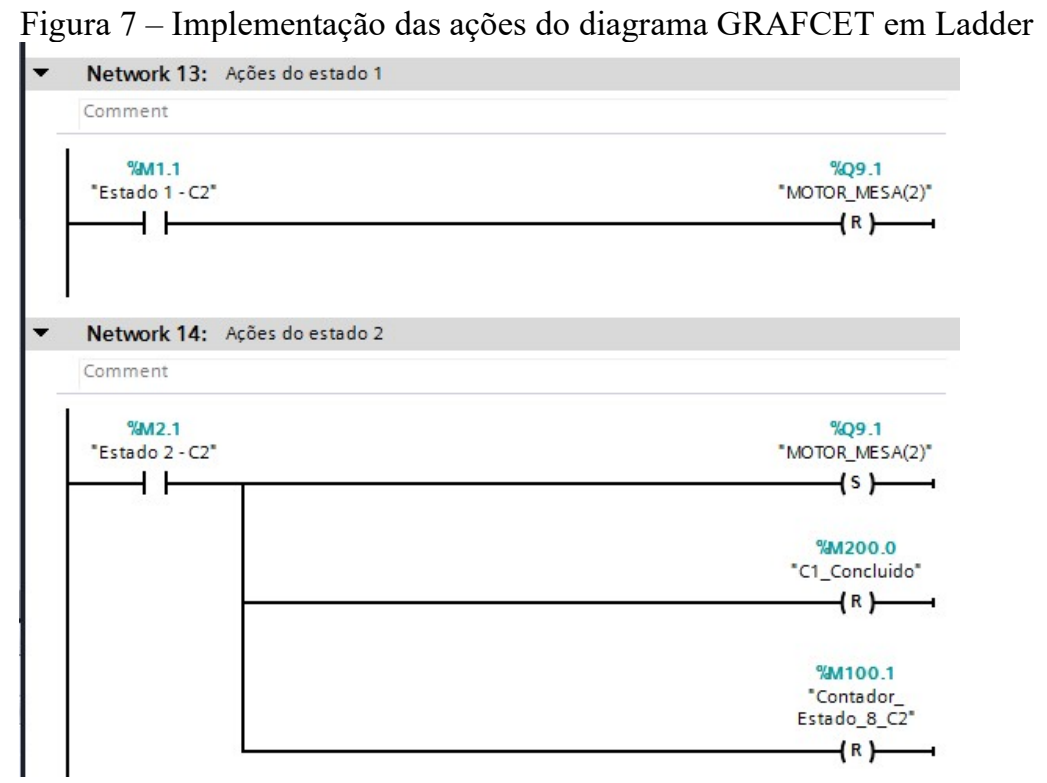

Fonte: Autoral 


\subsection{Compilação e Testes}

Com a conclusão do programa em linguagem Ladder, o projeto foi compilado e gravado no CLP, foram observados alguns pontos de falha, mas com a metodologia adotada os problemas podem ser facilmente identificados, pois, basta observar qual passo não foi realizado ou realizado com problema.

Analisando o diagrama GRAFCET e comparando com o funcionamento indesejado, fazse o ajuste no diagrama, uma vez resolvidos os problemas, o diagrama Ladder precisa ser atualizado no CLP, levando a planta de manufatura a funcionar corretamente, conforme o que foi definido.

\section{CONSIDERAÇÕES FINAIS}

A automação se faz presente nos mais simples processos da vida cotidiana, pois pode substituir tarefas físicas e mentais, árduas ou de alta periculosidade, bem como nas atividades mais complexas dentro de uma indústria, o que a torna de suma importância para o avanço da tecnologia. Para as indústrias, ela proporciona um aumento na quantidade e na qualidade de produção, o que gera um crescimento na eficiência e na competitividade entre as empresas, ocasionando preços mais acessíveis. Sendo necessários profissionais capacitados e atualizados, no que diz respeito ao uso e ao desenvolvimento das tecnologias mais modernas na área da automação industrial. É por isso que seu estudo e desenvolvimento se fazem tão necessários nos dias de hoje.

É difícil falar em automação sem envolver o CLP, pois desde a sua concepção, vem ganhando espaço e substituindo os antigos acionamentos realizados com relés eletromecânicos e são utilizados nos mais diversos processos. Desta forma, a abordagem acadêmica realizada neste trabalho contribui na formação do engenheiro eletricista, fornecendo uma visão ampla do controle de processos industriais, possibilitando a resolução de outros problemas seguindo a mesma metodologia.

O objetivo do trabalho, que era o desenvolvimento de projeto de automação de uma planta de manufatura utilizando CLP, foi alcançado, a planta funcionou como foi proposto. $\mathrm{O}$ conhecimento adquirido durante o estudo para análise do problema, projeto e implementação da solução foi fundamental para obter uma solução documentada, de fácil entendimento e que dará suporte para outros profissionais que poderão trabalhar com ela, e ainda quaisquer mudanças na linha de produção podem ser realizadas de forma rápida e fácil.

Todo o processo de criação do projeto apresentado foi de grande aprendizado, e os aspectos práticos envolvidos no controle de sistemas industriais poderão, com toda certeza, ser reaplicados no futuro, em um contexto profissional.

\section{REFERÊNCIAS}

BRAGA, C. M. P. Norma IEC 1131-3. DELT/ EEUFMG. 2001.

CAPELLI, A. Automação Industrial: Controle do movimento e processos contínuos. $2^{\mathrm{a}}$ edição. Érica, 2008.

FAUSTINO, M. R. Norma IEC 61131-3: Aspectos históricos, técnicos e um exemplo de aplicação. Dissertação (Mestrado) - Escola Politécnica da Universidade de São Paulo, 2005. 
GOEKING, W. Da máquina a vapor aos softwares de automação. O Setor Elétrico, Maio 2010.

GROOVER, M.P. Automação Industrial e Sistemas de Manufatura. $3^{\text {a }}$ edição. Pearson, 2010 .

Master Guide - Sistema Flexível de Manufatura. DK8 Tecnologia Educacional. $5^{\text {a }}$ edição, 2015.

Módulo 3 - Automação de Processos Industriais. Centro de treinamento de clientes - CTC. WEG, 2018.

PETRUZELLA, F. Controladores Lógicos Programáveis. 4a edição. AMGH, 2014.

PRUDENTE, F. PLC S7-1200: Teoria e Aplicações. Rio de Janeiro: LTC, 2014.

Siemens AG. S7-1200 Programmable controller - System Manual. [S.1.], Abril 2012.

Siemens AG. Módulo TIA Portal 031-100 - Fundamentos da Programação com SIMATIC S7-1200. [S.1.], Fevereiro 2016.

SILVEIRA, P.R. Automação e Controle Discreto. 4ª edição. Érica, 2002.

\title{
DEVELOPMENT OF A AUTOMATION PROJECT FOR A MANUFACTURING PLANT USING GRAFCET METHODOLOGY AND IMPLEMENTATION USING LADDER LOGIC
}

\begin{abstract}
Automation can be defined as the technology through a process or procedure that runs without human assistance. The art of controlling is as old as human needs in enhancing their own senses. Even when advanced technologies were not available, men maintained quality in tools and developed efficient projects directioned by their own demanding requirements. Although there are many equipment involved in automating directly and indirectly a given process, the Programmable Logic Controller (PLC) is one of the most important. PLC started being used in the late 1960s in the automotive industry in order to shorten machine downtime in the production environment. Since the assembly line was dynamic in relation to the car model to be produced, a simple change in production meant changes in the electrical connections between the electromechanical relays on the huge control panels. The purpose of this article is to develop an automation project for a manufacturing plant using the Siemens S7-1200 family PLC. The GRAFCET methodology was used, since the process is essentially sequential and the PLC used does not support this programming language. After developing the GRAFCET diagrams, they were implemented with Ladder logic. Several steps necessary for the development of an automation project were explored, from the detailed analysis of the system operation to the controller programming in the Siemens TIA Portal programming environment.
\end{abstract}

Keywords: Control and automation. CLP. GRAFCET. Ladder logic. 